\title{
VINTE ANOS - FILME DE ALICE DE ANDRADE
}

TWENTY YEARS - ALICE DE ANDRADE'S FILM

\begin{abstract}
Andréa Rodrigues ${ }^{1}$, Vivian Heringer Pizzinga ${ }^{2}$
${ }^{1}$ Universidade do Estado do Rio de Janeiro (UERJ), São Gonçalo, RJ, Brasil andrearodrigues.letras@gmail.com

${ }^{2}$ Centro Federal de Educação Tecnológica Celso Suckow da Fonseca (CEFET-RJ), Rio de Janeiro, RJ, Brasil

vivanhp@globo.com
\end{abstract}

Recebido em 30 jul. 2018

Aceito em 3 set. 2018

Vinte anos. Direção de Alice de Andrade. Rio de Janeiro: Montanha Russa Cinematográfica, 2016.

Ao cotejar momentos diferentes na vida de três casais cubanos, num intervalo de cerca de duas décadas, Alice de Andrade traz, no documentário Vinte Anos', algumas imagens do país misturadas a algumas "Cubas" possíveis e a outras, às quais talvez não tenhamos alcance, tecendo uma espécie de jogo entre caminhos e escolhas individuais e coletivas. O filme, que foi premiado no festival de Brasília e estreou no Brasil em 2018, mescla a trajetória de Cuba (tangenciando-a, sem entrar em méritos políticos mais aprofundados) às trajetórias individuais das famílias retratadas, evocando tanto os caminhos que foram possíveis quanto os que são, ainda, provisórios (e não há o que não seja, afinal). E esta é uma das joias do documentário: independentemente de qualquer interpretação que se queira fazer da história de Cuba, das medidas adotadas no passado, dos rumos do presente, o filme dá a conhecer um pouco da história do país pela narrativa dos próprios cubanos, com seus modos de existência que os levaram a inventar modos de sobrevivência - e não se trata aqui apenas de uma sobrevivência de natureza física, mas também ideológica e emocional. Este último viés é o foco do filme,

\footnotetext{
Trailer disponível em: https://www.facebook.com/pg/vinteanosfilme/about/?ref=page_internal
} 
uma vez que estamos falando de família, de afetos, de separações e reencontros.

Temos, de fato, um pouco de tudo: pessoas que resolveram não abandonar a ilha por nada, nem com as dificuldades existentes, outras que, sim, precisaram sair do país e deixar parte de suas famílias para trás, sentindo a falta dos seus ao abraçar o lugar de estrangeiros em outras paisagens, pessoas que escolheram a saída para estudar e permanecem fora de suas casas e, o que é também fundamental, a equipe de documentaristas brasileiros trazendo o olhar de fora que escolhe e edita as imagens, que compara tempos e espaços, que forja uma espécie de álbum de memórias imagético e afetivo que nos faz pensar nas mudanças.

Ao chegar à casa de Miriam e Andrés, depois de vários anos, Alice e sua equipe são muito bem recebidos. $O$ entusiasmo faz com que Miriam ultrapasse a borda da cena e cumprimente a assistente de câmera e o próprio câmera. Seu marido, Andrés, aparecendo logo depois, reconhece o câmera e conversa com ele em meio à filmagem. São detalhes de cenas que fazem pensar em Favret-Saada e a afetação como forma de conhecimento. Como aponta a autora, em seu artigo "Ser afetado" (2005), ao questionar o trabalho do etnógrafo que se coloca no lugar da verdade e de desqualificação da palavra do nativo em suas pesquisas de campo, é preciso se deixar afetar, é preciso redimensionar a noção de afeto e abdicar de certo posicionamento de conhecimento para comungar da vida e dos afetos narrados. É preciso abandonar a posição de visão objetiva de uma verdade sem distorções e, com isso, ter ciência de que o que se narra e o que se compreende de um lugar diferente do nosso é o que se pode narrar e o que se pode compreender, com limites inerentes a histórias pessoais, modos de vida, perspectivas culturais, entre outros.

Logo de início vemos que o documentário retoma outro, o curta Luna de Miel, feito também por Alice de Andrade, em 1992, época em que esses três casais - Miriam e Andrés; Marlene e Mario; Silvia e Danilo - estavam ainda se 
casando. Em vários momentos temos as famílias assistindo a trechos das entrevistas do casting e do próprio Luna de Miel e, nessas cenas, Vinte Anos se transforma numa espécie de metafilme, num filme sobre outro(s) filme(s), sobre como as pessoas se (re)veem na tela de uma TV e podem comentar se ainda pensam ou não daquele modo, se têm ou não os mesmos sentimentos. Em alguns momentos são mostrados os negativos feitos em 1992, que alguém pinta e borra, como se fosse ali a memória resgatada, o tempo permitindo a revisitação aos fatos passados, imprimindo suas marcas nas imagens. Essa intervenção sugere, com o uso da metalinguagem e da metáfora imagética, a ressignificação de histórias e lembranças que é inerente a qualquer retomada do passado, seja feita, por exemplo, na intimidade de um consultório ou na produção de um filme.

Para além da estética proposta de traçar um paralelo entre o filme atual e as entrevistas do casting do filme anterior, temos ainda o paralelo de biografias, que se descortinam aos poucos, sem linearidade, mostrando um percurso de trabalho e dificuldades, não apenas em Cuba, mas nos países escolhidos por esses cubanos que se tornaram imigrantes.

Um exemplo interessante é o de Danilo, que, com Silvia e o filho do casal, foi morar nos Estados Unidos e conta que chega a trabalhar em três lugares diferentes por dia, mudando frequentemente de trabalho. Danilo compara essa situação ao período em que morava em Cuba, quando trabalhou 17 anos no mesmo lugar. Essa contradição já é interessante para pensarmos a diferença de regimes econômicos e políticos: em primeiro lugar, sabe-se que, com a (nem tão) nova ideologia gerencial e o capitalismo financeiro que predomina desde a última crise do petróleo, a "flexibilidade" como bandeira utópica do novo milênio exige que façamos mil coisas ao mesmo tempo (ter três trabalhos encaixa-se exatamente aí). A ideia de longas carreiras e planejamento a longo prazo de vidas e trabalhos deixa de ter importância, não é mais desejável, como Richard Sennett aponta em $A$ corrosão do caráter (2005), além de diversos autores que vêm analisando as mudanças no mundo do trabalho a partir da financeirização do capital (Ricardo Antunes, sociólogo 
brasileiro, é um deles). No caso de Danilo, o excesso de trabalho e a variedade de postos de emprego ao longo da semana diz respeito à falta de escolha: ele precisa de dinheiro para sobreviver e sustentar sua família. Depois de três anos, quando voltam a Cuba e ainda no aeroporto, Silvia, aos prantos, abraça a filha e a neta, que tiveram de permanecer em Cuba. No percurso do aeroporto para casa - agora da filha -, a família aparece num carro antigo que o capitalismo extinguiu dos países "bem-sucedidos". Silvia e Danilo comentam, em tom de brincadeira, que estão andando numa "lata velha" e pedem para ligar o "ar condicionado". A alegria retratada, comparada às cenas em que dirigem seu carro, em silêncio, nas longas ruas bem asfaltadas de Miami, é emblemática do afeto presente no retorno à casa natal.

Outro aspecto interessante que Vinte Anos aborda é o da estrangeiridade e a forma como ela atravessa a vida de alguns personagens. Voltando ao casal Silvia e Danilo, o modo como têm de lidar com a língua inglesa, quando estão em Miami, evidencia as dificuldades, os estranhamentos e certo constrangimento. Silvia exerce a função de arrumadeira num grande hotel, cujos corredores e quartos percorre em silêncio, recolhendo roupas de cama e garrafas vazias. Num dado momento, ela sai com seu filho para comprar roupa e, na loja, o vendedor the pergunta algo que ela não compreende. Diante desse desencontro de linguagens e culturas, tudo o que Silvia consegue responder é "little english", sorrindo e voltando a ficar em silêncio. Assim como Silvia, Danilo e o filho também relatam dificuldades por conta da língua e a impossibilidade em contorná-las pelo fato de que, diante do excesso de trabalho, torna-se inviável um tempo de estudo para aprender a língua. $\mathrm{Na}$ Costa Rica, a filha do casal Marlene e Mario conta como estranhou morar em outro país, com outra família, outra cultura, ainda que latina.

Algumas cenas estabelecem ainda uma conversa entre imagens de Cuba e outras de fora, dos que ficaram no país e daqueles que tiveram de emigrar. É o caso das cenas que mostram Silvia limpando seu jardim em Miami enquanto a filha que ficou em Cuba está também limpando a casa que sua mãe deixou para ela. Ou as cenas que mostram a irmã que toca violino na 
Costa Rica enquanto a outra toca clarinete em uma pequena varanda de sua casa cubana- em que mora com a mãe, Marlene, já separada de Mario - que, por sua vez, após subir muitas escadas e passar por vários cômodos em ruínas, abre a janela de sua casa e nos dá a imagem do mar - que em alguns momentos a filha de Silvia olha, de Cuba, enquanto os pais o fitam, sozinhos numa praia americana.

Esses paralelos e a nostalgia que evocam ajudam a apontar que a estrangeiridade também está presente em Cuba, entre aqueles que ficaram. $\mathrm{O}$ estranhamento que acomete aqueles que se deparam com outras culturas, ao se distanciarem das suas, também parece estar prestes a acontecer entre as pessoas que não saíram do país, uma vez que, como a diretora comenta em sua narrativa em off no início do documentário, Cuba, diante das mudanças iminentes, pode se tornar um outro lugar.

À guisa de conclusão, o filme tem êxito ao nos colocar dentro da vida de seus personagens e nos fazer chegar bem perto da saudade que Marlene tem de sua filha, moradora agora da Costa Rica; da alegria de Silvia no aeroporto de Havana, ao rever filha e neta; da força de Miriam e Andrés, que moram num pequeno apartamento com sua grande família em Cuba. Ao fim e ao cabo, o que o filme suscita, para além de análises políticas e econômicas, é certa saudade que ficamos de Cuba, conhecendo ou não o país, querendo ou não conhecê-lo - e que pode atingir mesmo aqueles que foram a Cuba como turistas ou lá ficaram por poucos dias. Saudade do que não conhecemos é, portanto, um dos afetos que Vinte Anos, de Alice de Andrade, provoca em alguns de nós.

\section{REFERÊNCIAS:}

FAVRET-SAADRA, Jeanne. Ser afetado. Trad. de Paula Siqueira. Cadernos de Campo, n. 13, pp. 155.161, 2005.

SENNET, Richard. A corrosão do caráter: as consequências pessoais do trabalho no novo capitalismo. 9. ed. Rio de Janeiro: Record, 2005. 


\section{Sobre as autoras}

\section{Vivian Heringer Pizzinga}

Escritora, psicóloga do CEFET-RJ, doutoranda em Saúde Coletiva no Instituto de Medicina Social da UERJ e Mestra em Saúde Coletiva pela mesma instituição. Tem três livros publicados, além de vários contos em coletâneas. Escreve resenhas sobre teatro e cinema para a revista Diversos Afins e para o site Ambrosia.

\section{Andréa Rodrigues}

Doutora em Letras (PUC-Rio), com Pós-Doutorado na linha de pesquisa Memória e Linguagem (UNIRIO). Mestra em Linguística pela UFRJ. Professora do Programa de Mestrado Profissional em Letras e do Departamento de Letras da FFP-UERJ. 